\title{
Rapid quantification of epigoitrin in the extraction process of Radix Isatidis using near infrared spectroscopy
}

\author{
Caixia $\mathrm{Li}^{1,2}$, Wenjing Huang ${ }^{1,2}$, Qian Wang ${ }^{1,2}$, Zhiwei Huang ${ }^{1}$ and Shikai Yan ${ }^{1,3^{*}}$ \\ ${ }^{1}$ Institute of Traditional Chinese Medicine, Guangdong Pharmaceutical University, Guangzhou 510006, China \\ ${ }^{2}$ College of Traditional Chinese Medicine, Guangdong Pharmaceutical University, Guangzhou 510006, China \\ ${ }^{3}$ School of Pharmacy, Shanghai Jiao Tong University, Shanghai 200240, China
}

\begin{abstract}
Near-infrared Spectroscopy (NIR) is widely accepted as an efficient technology for process control in the production of traditional Chinese medicine (TCM). This study was to establish a NIR-based approach to determining epigoitrin of Radix Isatidis during temperature-controlled extraction process. 86 extracts of Radix Isatidis were prepared in $50{ }^{\circ} \mathrm{C}$ water for 4 hours, and were randomly divided into validation set and calibration set. The concentration of epigoitrin of each sample was determined by HPLC/UV, and correspondingly NIR spectra of those samples were also acquired. Partial least square (PLS) algorithm was utilized to develop a predictive model on NIR spectra data and contents of epigoitrin in samples of calibration set. The model displays good performance with acceptable values of SECV, SEC, LV and $\mathrm{R}^{2}$, and it was applied to predict the concentration of epigoitrin in samples of validation set from their NIR data. As a result, the model produced accurate result with little deviation between predicted values and experimental values. The proposed NIR method is expected to be developed as a promising approach for process control in TCM production.
\end{abstract}

\section{Introduction}

Radix isatidis, is a commonly used traditional Chinese medicinal (TCM) material for antivirus uses in most cases which was recorded in the Pharmacopoeia of the People's Republic of China 2015 (ChP 2015) ${ }^{[1] .}$ Pharmacology studies indicated its biological activities including antiviral activity, antibacterial activity, antiendotoxin, anti-immunity, anticancer and suppressing monoaminoxidase ${ }^{[2-4]}$. Radix isatidis and its preparations have been widely used to treat plague and seasonal toxins, fever, sore throat, macula, papules, mumps, scarlet fever, facial erysipelas and swollen abscesses ${ }^{[1]}$. Particularly, Radix isatidis attracts sharprising attention worldwide due to its exact efficacy to prevent the severe acute respiratory syndrome (SARS) and swine flu pandemic ${ }^{[5-6]}$. Alkaloids were generally considered as major antiviral components thereof ${ }^{[7-8]}$, among which epigoitrin is one of the most important alkaloid compounds (see chemical structure in Fig.1) with significant antimicrobial activity ${ }^{[9-10]}$.

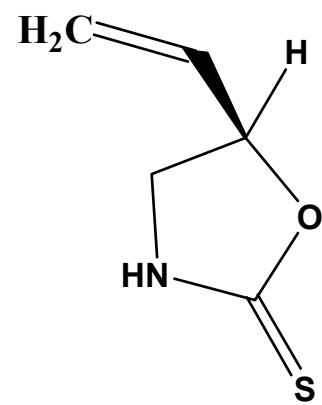

Fig. 1. Chemical structure of epigoitrin

Common extraction method of TCM, such as decoction and heating reflux, requires high temperature. Thus, it is not an appropriate choice for the extraction of thermally unstable compounds. Epigoitrin is such a compound, and will be decomposed at temperature over $60{ }^{\circ} \mathrm{C}{ }^{[11]}$. Therefore, temperature-controlled extraction is needed for the preparation of epigoitrin from Radix Isatidis.

Conventional method for detecting epigoitrin is by high performance liquid chromatography (HPLC). However, it is time-consuming and inappropriate for real-time monitoring ${ }^{[12]}$. In recent two decades, nearinfrared spectroscopy (NIRS) was ever-increasingly applied as a powerful process analysis technology (PAT) in agriculture ${ }^{[13-14]}$, environment ${ }^{[15-16]}$, chemical industry [17-18], and as well TCM production field ${ }^{[19-20]}$. NIRS may provide an alternative method to determine epigoitrin, which is superior to common analytical method due to

\footnotetext{
* Corresponding author: shkyan@126.com
} 
advantages of rapidness, nondestruction and environment friendliness ${ }^{[21]}$. To date, there is no NIRSbased approaches reported for process control on epigoitrin extraction from Radix Isatidis.

In this study, epigoitrin was extracted from Radix Isatidis by temperature-controlled extraction and NIRSbased approach were established to determine epigoitrin for process control. The partial least-square (PLS) algorithm was utilized to develop a predictive model in this research. The proposed approach was expected to be developed as a promising technology for the process control in TCM production.

\section{Materials And Method}

\subsection{Materials}

The Agilent 1260 High performance liquid chromatograph was used to analyze Radix Isatidis solutions in this study. Near infrared spectrometer purchased from Bruker (Germany) was used to collect NIR spectrum. High speed multifunction pulverizer purchased from Tianjin Taisite Instrument was used to comminute medicinal materials. The Chemometrics analysis system (THUNIR V3.0) from Tsinghua University was utilized to develop quantitative model of epigoitrin.

HPLC-grade methanol, acetonitrile for HPLC analysis were purchased from Merck (Germany). Epigoitrin was purchased from Sichuan Weikeqi Biological Technology and its purity was $99.00 \%$.

\subsection{Methods}

\subsubsection{Sample preparation}

All analytical determinations were conducted in triplicate. The Radix Isatidis $(100.0 \mathrm{~g})$ were pulverized extracted in $3 \mathrm{~L}$ water at $50{ }^{\circ} \mathrm{C}$ for $4 \mathrm{~h}$. Take a sample $(5$ $\mathrm{ml}$ ) every $5 \mathrm{~min}$ from the beginning. A total of 86 samples were collected and stored at $4{ }^{\circ} \mathrm{C}$.

$1.33 \mathrm{mg}$ epigoitrin was accurately weighed and dissolved in $10 \mathrm{ml}$ volumetric flask with methanol. Then it was diluted to $2.66 \mu \mathrm{g} \cdot \mathrm{ml}^{-1}, 6.65 \mu \mathrm{g} \cdot \mathrm{ml}^{-1}, 13.3 \mu \mathrm{g} \cdot \mathrm{ml}^{-1}$, $26.6 \mu \mathrm{g} \cdot \mathrm{ml}^{-1}$ and $66.5 \mu \mathrm{g} \cdot \mathrm{ml}^{-1}$ respectively.

\subsubsection{HPLC method}

Epigoitrin was analyzed according to the method of ChP 2015. A Sharpsil-AQ $\mathrm{C}_{18}$ column $(4.6 \mathrm{~mm} \times 250 \mathrm{~mm}, 5$ $\mu \mathrm{m})$ was used to analyze the epigoitrin at $245 \mathrm{~nm}$ at the column temperature of $25{ }^{\circ} \mathrm{C}$. The injection volume of each sample was $5 \mu \mathrm{l}$. The chromatography condition was isocratic elution and mobile phase combined with methanol and water $(7: 93)$ at the rate of $1.0 \mathrm{ml} \cdot \mathrm{min}^{-1}$. All samples were filtered by $0.45 \mu \mathrm{m}$ membrane before analysis.

\subsubsection{NIR Spectra acquisition}

NIR spectra of Radix Isatidis solutions were scanned twice in the range of $12000-4000 \mathrm{~cm}^{-1}$ by Bruker NIR Analyzer (Bruker, Germany). Air absorbance was regarded as the background absorption ${ }^{[22]}$.

\subsubsection{Destination monitoring}

The THUNIR Online software was used to predict the concentration of epigoitrin in the extraction process of Radix Isatidis. The samples with the same trend of were selected to construct prediction model.

\subsubsection{Data processing}

THUNIR software was utilized to develop model. NIR spectra and related concentration values were checked before grouping. All samples were divided into calibration set and verification set randomly. A total of 67 samples were used to develop calibration model and the rest of 19 samples were used for validation sets.

The spectra were pre-treated before modelling. Spectral pre-treatment methods such as standard normal variate transformation (SNV), normalization, convolution smoothing, one-dimension convolution (one-DC), multiplicative scatter correction (MSC), two dimension convolution (two-DC), were used to deal with the spectra data ${ }^{[23]}$

Different variable selection methods such as full wavelength method, correlation coefficient method, related component method, and iterative optimization method were used to select the wavelength.

PLS algorithm was utilized to obtain the relationship between the true values and NIR spectra. To evaluate the quantitative model, Standard Error of Cross Validation (SECV), Standard Error of Calibration (SEC), determination coefficient $\left(\mathrm{R}^{2}\right)$ and latent variables (LV) were used to optimize the quantitative analysis model.

\section{Results And Discussion}

\subsection{NIR Spectra}

As shown in Fig. 2, there were strong absorbance in the wavenumber ranges of $7200-6200 \mathrm{~cm}^{-1}$, and $6100-5500$ $\mathrm{cm}^{-1}, 5000-4545 \mathrm{~cm}^{-1}$, which related the overlap of several $\mathrm{C}-\mathrm{H}$ second overtones, the $\mathrm{O}-\mathrm{H}$ first stretch of $\mathrm{H}_{2} \mathrm{O}$, and the overlap of several $\mathrm{C}-\mathrm{H}$ first stretch overtones, respectively ${ }^{[24]}$. 


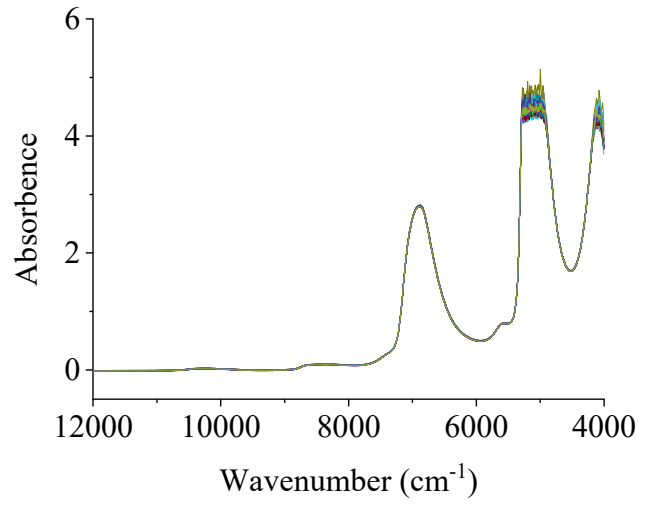

Fig. 2. Typical raw spectra of Radix Isatidis solutions

\subsection{Determination of reference values by HPLC}

Chromatogram of Radix Isatidis solution was shown in Fig. 3. The RSD values of precisions, repeatability, stability and recovery were respectively $1.03 \%, 0.451 \%$, $1.82 \%, 3.11 \%$. The calibration curve was $\mathrm{Y}=29$ $199 \mathrm{x}+29.028$, and $\mathrm{R}^{2}$ was 0.9999 . Its linear range was $0.00266-0.133 \mathrm{mg} \cdot \mathrm{ml}^{-1}$. References data of epigoitrin were showed in Table 1.

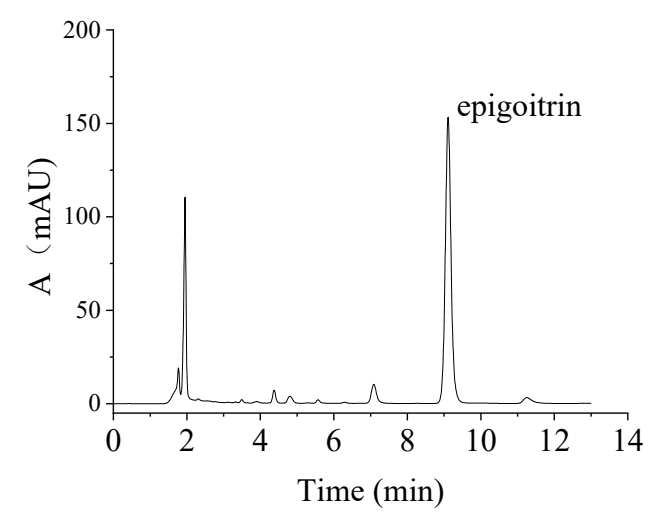

Fig. 3. HPLC chromatogram of Radix Isatidis solution

Table 1 References data of epigoitrin $(\mu \mathrm{g} / \mathrm{ml})$

\begin{tabular}{lcccc}
\hline & Min & Max & Mean & SD \\
\hline Calibration set & 31.01 & 60.02 & 47.90 & 0.0077 \\
Validation set & 31.00 & 57.47 & 47.97 & 0.0086 \\
\hline
\end{tabular}

\subsection{Temperature investigation}

Different extraction temperature had been investigated in this study. Six batches of Radix Isatidis $(1.0 \mathrm{~g})$ were pulverized and extracted in $3 \mathrm{~L}$ water for $4 \mathrm{~h}$. The temperatures were set every $10{ }^{\circ} \mathrm{C}$ at the range of 40 $80{ }^{\circ} \mathrm{C}$ and $100{ }^{\circ} \mathrm{C}$. As shown in Fig. 4, it was noticed that the concentratio of epigoitrin showed an obvious declining trend when the temperature was over $60{ }^{\circ} \mathrm{C}$. This was consistent with previous study ${ }^{[11]}$. The concentration of epigoitrin achieved the highest at $50^{\circ} \mathrm{C}$. So, in this study, Radix Isatidis were extracted at $50^{\circ} \mathrm{C}$.

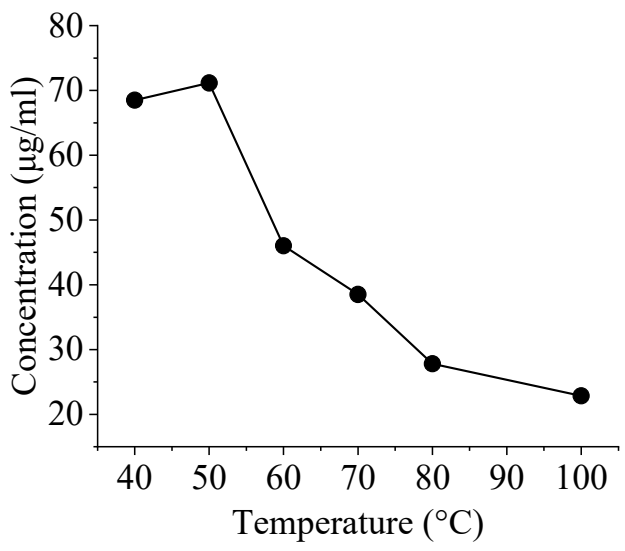

Fig. 4. Concentration of epigoitrin in different temperature

\subsection{End point monitoring}

THUNIR Online analysis software was utilized to analyze the Radix Isatidis solutions in temperaturecontrolled extraction. The wavenumbers range was $12000-4000 \mathrm{~cm}^{-1}$. As shown in Fig. 5, the trend become smooth finally. This indicated that it has been extracted completely and reaches a stable state in the end.

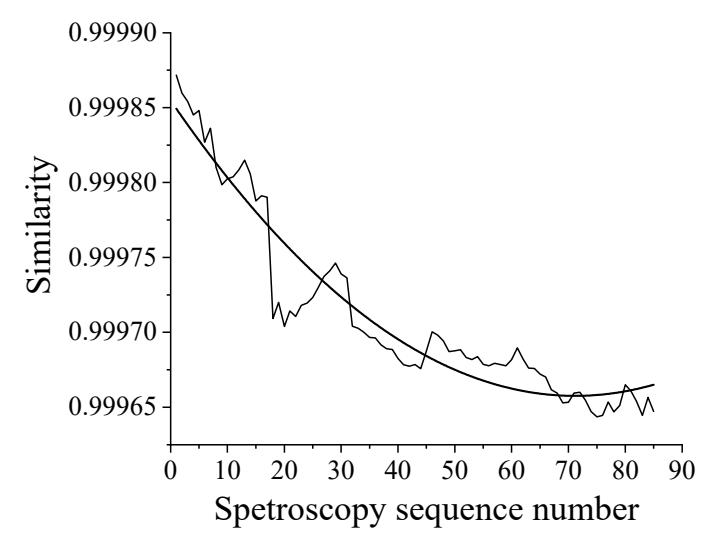

Fig. 5. The process analysis of Temperature-controlled extraction

\subsection{Modeling}

\subsubsection{Spectral pretreatment and wavelength selection}

NIR spectra contain a lot of information, and they include instrumental and experimental artifacts [24]. Scattering, noise exist in NIR spectra which would decrease the accuracy of model. unwanted artifacts should be removed. So the spectra should be preprocess before modelling. This study mainly used four pretreatment methods, including standard normal variate transformation, normalized, convolution smoothing, multiplicative scatter correction.

THUNIR software was used to combine the data of NIR and HPLC with different pretreatment methods, wavelength selection methods and PLS. The best model would be obtained according to the value SECV, SEC and $\mathrm{R}^{2}$. The effects of spectral pretreatment method and 
$\mathrm{LV}, \mathrm{SEC}, \mathrm{SECV}$ and $\mathrm{R}^{2}$ on the models were investigated. The best spectral pre-processing method was standard normal variate transformation method.

Table 2 Spectral pretreatment methods and model parameters of epigoitrin

\begin{tabular}{cccccc}
\hline Model & $\begin{array}{c}\text { Pretreatmen } \\
\text { t methods }\end{array}$ & SECV & SEC & LV & $\mathrm{R}^{2}$ \\
\hline 1 & Raw & 0.9768 & 0.7278 & 14 & 99.13 \\
2 & $\begin{array}{c}\text { Normalizati } \\
\text { on }\end{array}$ & 0.4936 & 0.3075 & 9 & 99.84 \\
3 & SG & 1.0140 & 0.5725 & 11 & 99.46 \\
& smoothing & & & \\
4 & MSC & 0.4636 & 0.3048 & 8 & 99.85 \\
5 & SNV & 0.6013 & 0.5195 & 5 & 99.56 \\
\hline
\end{tabular}

SNV: standard normal variate; MSC: multiple scatter correction; SECV: standard error of cross validation; LV: latent variable number; SEC: standard error of calibration.

\subsubsection{Evaluation for the model}

The quantitative model would achieve better prediction performance when the correlation coefficient $\left(R^{2}\right)$ value was close to 100 and had lower SECV value, SEC value and LV value. As known in Table 2, The $\mathrm{R}^{2}$ value of model 5 was $99.56 \%$ and this model had lower SECV value (0.6013), SEC (0.5195) value and LV value (5).

Fig. 6A showed the changes of $\mathrm{R}^{2}$ and SECV (SEC) with LVs for model 5. Fig. 6 shows increasing $\mathrm{R}^{2}$ value, while the value of SECV (SEC) decreased along with LVs increased [22]. It indicated that the model became more and more robust. However, after 5 PCs, the value of $\mathrm{R}^{2}$ and SECV (SEC) tend to stable. So, the optimal LVs for model 5 was 5 PCs. As known in Fig. 6B, the true values and the predictive values of calibration model are similar and the correlation coefficient value was 0.9955. This indicated that the model had good predictive effect.
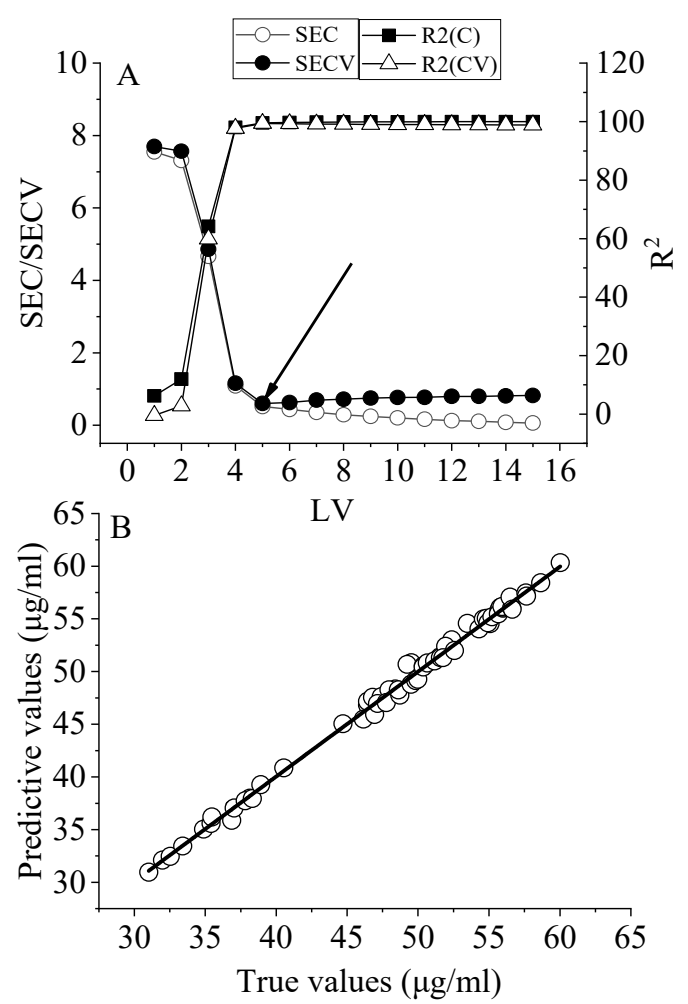

Fig. 6. A: $\mathrm{R}^{2}$ (C: calibration; CV: cross validation) and SECV for the PLS model; B: true values and predictive values of calibration set

\subsubsection{Model validation}

Nineteen samples were selected for external validation set to predict the concentration of epigoitrin. The true values and predicted values were shown in Fig. 7. The $\mathrm{R}^{2}$ value was 0.9945 . This indicated that the quantitative model of epigoitrin had a good prediction ability. The model will be better when the model has the lower LV value.

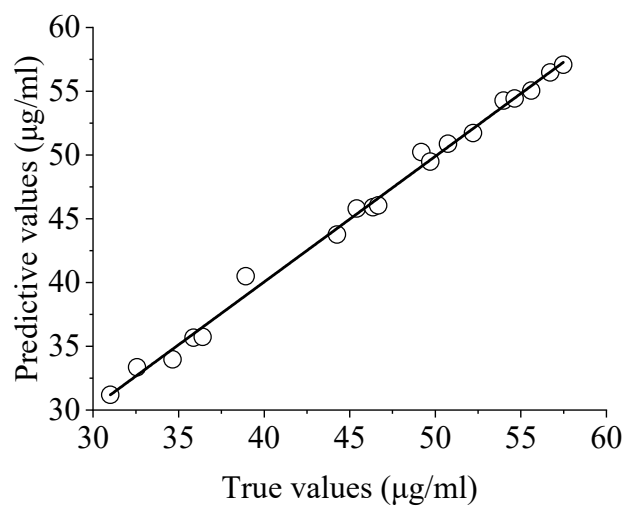

Fig. 7. the true values and predictive values of validation set

\section{Discussion}

This study proposed a promising NIR-based quantitative analysis approach which is expected to apply in rapidly determination of epigoitrin in the temperature-controlled 
extraction process. Compared with traditional laboratory methods, NIRS is more efficient, cost-effective, and environmentally friendly, and it can develop rapid quantitative models.

NIRS technology can be applied for rapid quantitative, qualitative analysis and quality evaluation of Chinese medicine and online monitoring in extracting. However, the near-infrared had low absorption and sensitivity to spectral information which affected the accuracy of compound measurement. What's more, it needs a lot of work to develop model in early study. Due to incomplete database model, the use of NIR technology is limited. Expanding and improving the spectral model system of drugs and improving the stability and accuracy of the model will become the focus of research. In spite of the limitation, with the continuous development and maturity of optical technology, computer hardware and software, chemometrics and drug analysis, NIRS technology will be more applied in the field of traditional Chinese medicine. It is more practical for the detection, identification and drug supervision of TCM ${ }^{[26]}$.

\section{References}

1. Pharmacopoeia of the People's Republic of China (Volumn I). 205-206(2020)

2. L.W. He, J.Y. Yang, W. Dong, Y.Y. Qing, J Pharm Res 34(1), 1-3 (2015)

3. Z.J. Du, H. Liu, Z.L. Zhang, P. Li, Int J Biol Macromol 58, 329-335(2013)

4. C. Qing, Chin Pharm Aff 23(6), 607-608 (2009)

5. C.W. Lin, F.J. Tsai, C.H. Tsai, Antivir Res 68(1), 36-42(2005)

6. Z. Yang, Y. Wang, S. Zhong, Mol Medrep 5(3), 793(2012)

7. S. Liu, J. Yan, H.L. Li, F.R. Song, Z.Y. Liu, Z.Q. Liu, S.Y. Liu, Chem J Chin Univ 31(6), 11371142(2010)

8. J. Peng, G. Fan, Y. Wu, J Chromatogr A 1091(1), 89-93(2005)

9. P. Xiao, W.Y. Ye, J.W. Chen, X, J. Li, Tradit Chin Med 36(3), 369-376(2016)

10. J.H. Su, R.G. Diao, S.G. Lv, X.D. Mou, K.F. Li, Selli, Serkan, Evid-based Compl Alt 2016, 1-8(2016)

11. Y.Q. An., Jiangsu Univ (2009)

12. F.F. Tao, H.B. Yao, F.L. Zhu, Z.N. Hruska, Y.L Liu, K. Rajasekaran, D. Bhatnagar, J Agr Food Chem 67(18), 5230-5239(2019)

13. H.J. Huang, Y.L. Yan, B.H. Shen, Z. Liu, J.C. Gu, S.M. Li, D.H. Zhu, X.D. Zhang, Q. Ma, L. Li, D. An, Spectrosc Spect Anal 34(5), 1253-1258(2014)

14. H.N. Feng, Q.T. Li, J.J. Lu, S.W. Li, L.P. Liu, A.L. Xia, J. Wang, J Instr Anal 28(12), 1460-1463(2009)

15. L. Wang, Y. He, Y.P. Wang, Y. Zhao, W. Li, X.R. Wang, L. Frank, Marin Environ Sci 23(2), 5860(2004)
16. H.B. Ma, Chongqing Univ (2006)

17. T. Wu, G.G. Fang, L. Liang, H.H. Cui, J Forestry Eng 1(2), 77-81(2016)

18. E.W. Yuan, X.L. Yan, D.H. Zhao, H.F. Han, Infrar Technol 38(1), 64-70(2016)

19. Y. Luo, W.L. Li, W.H. Huang, X.H. Liu, Y.G. Song, H.B. Qu, J Zhejiang Univ Sci B 18(5), 383392(2017)

20. X.L. Hu, Y. Bai, J.W. Lei, D.W. Zhang, M. Hao, Chin J Pharm Anal 36(3), 547-553(2016)

21. Foss North America. ISIscan \& WinISI Software Training Class (2008)

22. J.T. Xue, Y.F. Liu, L.M. Ye, C.Y. Li, Q.W. Yang, W.Y. Wang, Y. Jing, M.X. Zhang, P. Li, Spectrochim Acta A Mol Biomol Spectrosc 188, 611-618(2018)

23. X. Xiao, Y.Y. Hou, J. Du, Y. Liu, Y.J. Liu, L.Y. Dong, Q.L. Liang, Y.M. Wang, G. Bai, G.A. Luo, J Agr Food Chem 60(32), 7830-7835(2012)

24. J. Li, M. Zhang, F. Dowell, ACS Omega 3(5), $5355-$ 5361(2018)

25. J. Engel, J. Gerretzen, E. Szymańska, J.J. Jansen, G. Downey, L. Blanchet, L.M.C. Buydens, Trac-trend Anal Chem 50, 96-106(2013)

26. Q.N. Zhang, H.C. Zang, J Food Drug 19(4), 302305(2017) 